\title{
PUGNASENTRE MONARQUÍA Y ARISTOCRACIA POR EL CONTROL DE LOSALMOJARIFAZGOS COSTEROS Y OTROS DERECHOS ADUANEROS DE LA ANDALUCÍA ATLÁNTICA EN EL REINADO DE LOS REYES CATÓLICOS*
}

\author{
CONFLICT BETWEEN THE MONARCHY AND THE ARISTOCRACY \\ FOR CONTROL OF THE ALMOJARIFAZGOS AND OTHER \\ CUSTOM S DUTIES ON THE ATLANTIC COAST OF ANDALUSIA \\ IN THE REIGN OF THE CATHOLIC KINGS
}

J OSÉ D A M IÁN GonZÁ LEZ A RCE
Universidad de M urcia
http://orcid.org/0000-0002-3296-0554

Resumen: Entre la conquista a los musulmanes, a mediados del siglo XIII, y la primera mitad del siglo XV, la práctica totalidad de la costa atlántica andaluza fue entregada por la monarquía castellana a poderosos señores. En su mayor parte, se trató de grandes aristócratas que pretendieron recaudar en sus señoríos, además de otras rentas, el impuesto sobre el comercio exterior por vía marítima conocido como almojarifazgo. Éste, en teoría, pertenecía a la Corona y su cobro se hallaba centralizado en la cercana ciudad de Sevilla y en su aduana. Tras varias centurias de debilidad monárquica, a finales del siglo XV los Reyes Católicos consiguieron, a través de numerosos y largos procesos judiciales, recuperar para la $\mathrm{H}$ acienda real estos gravámenes y retornar el control fiscal a la Corona de forma casi completa.

Palabras clave: impuesto; comercio; aduanas; hacienda real; A ndalucía; señoríos.

\begin{abstract}
Between the conquest of the $M$ uslims, in themiddl e of thethirteenth century, and the first half of the fifteenth century, virtually the entire the A tlantic coast of Andalusia was handed over to powerful lords by the monarchy. They werefor the most part great aristocrats who hoped to collect the tax on foreign trade by sea known as the almojarifazgo in their domains, along with other revenues. This tax theoretically belonged to the Crown. I ts collection was central ized in the nearby city of Seville and its customs house. A fter several centuries of monarchical weakness, in the late fifteenth century the Catholic Kings managed, through numerous lengthy judicial processes, to recover these levies for the royal treasury and to almost completely restore control of taxation to the Crown.
\end{abstract}

Keywords: tax; trade; customs; royal treasury; A ndalusia; lordships.

\footnotetext{
* Este trabajo ha sido realizado en el marco de los proyectos HA R 2013-45788-C 4-1-P "EI Negocio de la Fiscalidad": arrendamientos, gestión fiscal y deuda pública (fines siglo XV1556), y HAR2014-52469-C 3-1-P, Poder, fiscalidad y sociedades fronterizas en la Corona de Castilla al sur del Tajo. Siglos XIV-XVI, integrados en la red A rca Comunis.
} 


\section{SUMARIO ${ }^{1}$}

1. Introducción.- 2. La apropiación del almojarifazgo aduanero.- 2.1. Casa de A rcos.2.2. Casa de Medinaceli.- 2.3. Casa de M edina Sidonia.- 2.4. Casa de Béjar.- 2.5. Los comienzos del siglo XVI.- 3. Prestigio político.- 4. Conclusión.- 5. Bibliografía citada.

\section{INTRODUCCIÓN}

Como indicó ya hace bastantes años la profesora Quintanilla R aso, en un trabajo que podemos considerar como clásico sobre las haciendas señoriales, en la baja E dad M edia, la vía básica para la obtención de ingresos por parte de la nobleza fue la capacidad fiscal cedida por la monarquía al concederle señoríos; que aparece recogida en los privilegios de donación, según fórmulas generalmente estereotipadas². M ás adelante, la autora repasa la obra del primer investigador que puso su atención sobre la naturaleza jurídica de la renta señorial, S. de Moxó, y sus principales aportaciones. Caso de la triple división de la misma entre territorial, vasallática y jurisdiccional. La relativa poca fortuna del segundo término y concepto, vinculado a aquellos derechos señoriales que no son judiciales (jurisdiccionales) ni dominicales (territoriales) y que atienden al sentido de sumisión de los habitantes de un pueblo hacia el titular del lugar; entre los cuales se contaban los portazgos, peajes, monopolios y las alcabalas. Cómo la acepción de renta por vasallaje fue sustituida por renta señorial, más conveniente, ya que permitía ser aplicada a personas ajenas al señorío y, por tanto, no vinculadas ni sometidas personalmente al señor, como los mercaderes en tránsito. Y, finalmente, cómo una clasificación posterior, también tripartita, optó por diferenciar la renta entre territorial o solariega; fiscalidad jurisdiccional, que incluía los derechos vasalláticos o señoriales antedichos, pagados en reconocimiento de señorío y generalmente recibidos de la monarquía junto con la capacidad de hacer justicia y las labores de gobierno; y un nuevo concepto, la fiscalidad regaliana, o impuestos cedidos por los monarcas 0 arrebatados a la hacienda regia.

Según la anterior clasificación trina de la renta feudal, la mayoría de los tributos comprendidos en los almojarifazgos señoriales de la baja

\footnotetext{
${ }^{1} \mathrm{~A}$ breviaturas utilizadas: $\mathrm{AC}=\mathrm{A}$ cta Capitular; $\mathrm{A} \mathrm{GS}=\mathrm{A}$ rchivo General de Simancas; $\mathrm{AHN}=$ A rchivo Histórico $\mathrm{N}$ acional; $\mathrm{A}$ M J F = A rchivo $\mathrm{M}$ unicipal de J erez de la Frontera; $\mathrm{CC}=\mathrm{C}$ ámara de Castilla; $L C=$ L ibro de Copia; M S = M edina Sidonia; PR = Patronato Real; RGS = R egistro General del Sello; SN = Sección N obleza.

${ }^{2}$ Quintanilla 1982b, pp. 770-778; véase también 1982a.
} 
A ndalucía estarían encuadrados en los dos últimos apartados. A unque al gunos pudieron derivar del primer supuesto, al provenir de derechos teóricos sobre la propiedad de la tierra (diezmos sobre ciertos productos agrícolas o sobre labores de alfarería, fincas de recreo de época musulmana, etc.). A sí, principalmente, o bien fueron arbitrios fiscales cedidos por los reyes junto con la jurisdicción sobre el territorio, emanados de las labores de gobierno y justicia ejercidas directamente en él por el señor; o bien eran impuestos que en teoría debían haber sido cobrados por la Corona en el lugar, pero cuyo rendimiento, e incluso a veces su gestión y recaudación, se cedió en beneficio de los señores locales, generalmente a título provisional o temporal, 0 éstos simplemente se los arrebataron a la Hacienda en momentos de debilidad de las instituciones de gobierno. La diferencia entre unos y otros estaría en que las primeras imposiciones eran inherentes a las actividades gubernamentales otorgadas o reconocidas por la monarquía a los nobles, mientras que las segundas no tenían nada que ver con éstas, pero se demandaban en sus dominios para otros fines que trascendían los servicios en teoría prestados por ellos en favor de los lugareños, que sí les facultaban para exigir las primeras.

De este modo, una de las tareas, sin duda de las más importantes, concedidas por los reyes a los titulares de los señoríos jurisdiccionales eran las labores de defensa y protección de sus habitantes y de aquéllos que por allí transitasen. Esto es, se los dotó dentro de su ámbito territorial tanto de facultades bélicas, para la lucha contra los enemigos exteriores, como policiales, para la persecución y detención de los delincuentes interiores. A ctividades que había que financiar, para lo que los señores, junto con la jurisdicción territorial en la que ejercieron su poder, obtuvieron parte de las tributaciones allí recaudadas.

Conviene tener presentes ciertas reflexiones sobre los orígenes del Estado Moderno, al que los Reyes Católicos dieron forma. En palabras de Nieto Soria son varios los aspectos que lo definen: un orden político de poder globalizador; autoridad ejercida sobre un territorio definido y sus habitantes; monopolio de la coerción física; legitimidad emanada de la comunidad gobernada, sin dependencias exteriores; cierta autoridad moral; y un aparato de gestión con permanencia más allá de los gestores³.

L os señores de la baja A ndalucía costera recibieron la facultad de garantizar el orden público en sus territorios patrimoniales, y con él la seguridad de sus vías de comunicación, calles y mercados. L abores que no sufragaron con la exigencia de portazgos, que prácticamente no aparecen en ningún

\footnotetext{
${ }^{3} \mathrm{~N}$ ieto 2007 , p. 34.
} 
señorío, salvo al gún caso aislado como Niebla y Gibraleón; si bien no debemos olvidar que al gunos de los derechos que veremos más abajo sí resultaron en realidad simples portazgos. Junto a éstos, otras fuentes de financiación fueron las alcabalas. Las hubo en Sevilla, Córdoba, Jerez, A rcos, Sanlúcar, Niebla, Palos, M edina Sidonia, A Icalá de los Gazules... Se trató de un derecho exigido por la introducción, puesta a la venta o a veces el simple tránsito de productos por el municipio, generalmente a abonar solo por los forasteros, pues los lugareños estaban exentos de estas imposiciones por los artículos de su labranza y crianza e incluso de lo que importasen para su abastecimiento, según las franquezas contenidas en los fueros y cartas pueblas fundacionales. La tarifa más habitual para la importación solía ser del $5 \%$, por lo que a veces en lugar de como alcabalas estos gravámenes eran denominados por el tipo impositivo y se les llamaba veintenas. La tasa sobre la exportación solía ser del 2,5\%, y por tanto era designada como cuarentena. En ocasiones, los aranceles fueron del $10 \%$ y se conocieron como diezmos. En todo caso, estas alcabalas, a partir del siglo XIV Ilamadas viejas, para no confundirlas con la alcabala real instituida por Alfonso XI, precisamente inspirada en ellas, veintenas, cuarentenas o simples derechos de entrada y salida, fueron muy similares al propio almojarifazgo aduanero e incluso por tal fueron tenidos en algunos lugares 4 .

J unto a los dos casos anteriores, en los que la Corona cedió sin contradicciones a nobles y aristócratas estas rentas para que en sus solares garantizasen la seguridad y el orden, en ellos también pudieron exigir sin mayores problemas otras punciones más relacionadas con la venta en el mercado y el uso de pesos y medidas, como los almotacenazgos y corretajes, en los que no me detendré por no constituir propiamente exacciones sobre el tráfico comercial. No quedó tan clara, sin embargo, la naturaleza jurídica y, por tanto, la potestad para poder demandar al gunos otros tributos que adoptaron la forma de derechos de paso puntuales como tablas, calzadas, aduanas... que luego veremos, y que por ello fueron suprimidos o restringidos por los Reyes Católicos, al menos en teoría.

Dichos monarcas, claramente, y éste es el objetivo principal del trabajo que aquí comienza, lucharon por eliminar cualquier derecho señorial sobre el comercio marítimo exterior de la costa atlántica andaluza, gravado por un impuesto conocido desde el siglo XIV como almojarifazgo y cuyo cobro estuvo desde entonces centralizado en el partido del almojarifazgo mayor de Sevilla.

Se precisa, antes de continuar, una aclaración terminológica. El almojarifazgo inicial fue un conjunto de rentas pertenecientes a la hacienda

${ }^{4}$ Sobre estos aspectos, véase la obra de síntesis de L adero 2009. 
regia en al gunas poblaciones conquistadas al Islam al sur del Sistema Central, muchas de ellas antes exigidas por los emires musulmanes. Constituía el tesoro local del monarca castellano, administrado por su tesorero o almojarife. Generalmente, el tributo más importante de este conjunto heterogéneo era el canon sobre el comercio exterior; nótese que muchas de estos emiratos, taifas o reinos independientes antes de su ocupación no tenían una extensión mucho mayor que los posteriores señoríos bajomedievales. De modo que el arancel aduanero que lo gravaba, que solía ser del $10 \%$, en un principio denominado por ello como diezmo, para no ser confundido con otros diezmos fue pronto, a partir del siglo XIV, denominado también como almojarifazgo, a modo de sinécdoque en la que se tomó la parte por el todo. Finalmente, en la ciudad de Sevilla, desde dicho siglo, se formaron dos almojarifazgos, uno concejil, con las rentas cedidas por la Corona al municipio, entre ellas los almojarifazgos de los lugares y concejos de su tierra bajo jurisdicción de la capital; y el otro, el que seguía en poder del monarca, llamado mayor para diferenciarlo del primero. Este último estaba a su vez dividido en tres: el diezmo del aceite del Aljarafe; Ias rentas menudas, o toda suerte de derechos no aduaneros, similares a las alcabalas y almotacenazgo arriba vistos; y, el arancel sobre el comercio con el exterior del arzobispado y reino de Sevilla, o circunscripción fiscal, cobrado en la casa de la aduana o por sus agentes. Dicho arancel, a su vez, se fragmentó en otras tres rentas, a veces recaudadas por separado. Primero, la almonaima y cuenta de mercaderes: la almonaima eran los libros donde se asentaban los derechos abonados, o cuenta del cargo y descargo del mar, según un padrón del que conocemos una versión de 1491; y, la cuenta de mercaderes, el hecho de que cada importador reconocido tenía reservadas sus páginas en dichos libros de entrada y salida de la aduana. Segundo, el partido de las mercaderías, punción consistente en una al cabala sobre la primera venta de los objetos importados. Y, por último, la renta de Berbería, que gravaba específicamente el comercio con el M agreb5.

Los Reyes Católicos, como sus predecesores, consintieron que los señores territoriales percibiesen derechos sobre el tráfico comercial interior al partido fiscal del arzobispado de Sevilla y obispado de Cádiz, o reino de Sevilla. Fueron los portazgos, alcabalas, veintenas y cuarentenas antedichas con los que, en teoría, los poderosos podían garantizar la convivencia y la paz en las vías de comunicación y mercados. Incluso, pudieron tolerar que a veces gozasen de los impuestos sobre el comercio terrestre

\footnotetext{
${ }^{5}$ L adero 1969, pp. 72-78; 1982a, pp. 9-33. El estudio de detalle sobre la recaudación, arrendamiento y rendimientos del almojarifazgo sevillano supera con mucho el ámbito del presente trabajo. A sí, el citado diezmo del aceite ha requerido por sí solo de un extenso análisis, González 2012.
} 
con Granada, el diezmo y medio diezmo de lo morisco que les fuera concedido a algunos de ellos, sobre todo porque durante su reinado apenas fue efectivo, debido a que el estado casi permanente de guerra anulaba el comercio legal con dicho reino. Sin embargo, se mostraron intransigentes, como vamos a ver, en cuanto a permitir que dichos aristócratas percibiesen ingresos al gunos provenientes del tráfico marítimo, aunque les hubiesen sido dados por los monarcas precedentes o los hubiesen conseguido por la simple apropiación del antedicho almojarifazgo aduanero o la exigencia de nuevos gravámenes, todos ellos conocidos como derechos de cargo y descargo de la mar.

El motivo: que tales impuestos fueron tenidos por ellos como rentas anejas al señorío regio, esto es, que formaban parte de la susodicha fiscalidad regaliana, y que, tras ser cedidos en tiempos anteriores por la Corona o haber resultado sencillamente usurpados, quisieron que retornasen a la Hacienda real. Y ello, tanto por la relevancia económica que revistieron, ya que el almojarifazgo fue unos de los arbitrios ordinarios de mayor importancia por su volumen de ingresos para las arcas públicas, como por su simbolismo ideológico, pues el control de las fronteras exteriores era uno de los signos más evidentes de la soberanía política. No será preciso recordar aquí el especial interés y esfuerzo de los Reyes Católicos por mejorar ambos ámbitos de su gobernanza, el ejercicio del poder económico-fiscal y el político-institucional de la monarquía frente a la nobleza y la I glesia; aspectos que se ejemplificaban de forma conjunta en la potestad exclusiva que reivindicaron para poder cobrar el almojarifazgo y otras tasas aduaneras.

\section{LA APROPIACIÓN DEL ALMOJARIFAZGO ADUANERO}

En teoría, todos los artículos comerciales que entraban o salían del arzobispado de Sevilla y obispado de Cádiz, tanto de territorios ajenos a la Corona como de otros partidos fiscal es castellanos, por mar o por tierra, debían ser llevados a la aduana de la capital hispalense para abonar el al mojarifazgo. En la práctica, se dieron numerosas excepciones y licencias para permitir a ciertas localidades abastecerse directamente 0 a otras para actuar como puertos de carga y descarga, sobre todo en el caso de Jerez de la Frontera y Cádiz, y registrar allí las mercancías, lo que posibilitó un importante nivel de fraude, e incluso el contrabando organizado. En este sentido, en 1493, tras ser revertido a la Corona, el surgidero gaditano se hizo con la exclusiva del embarque y desembarque de mercancías con destino a, o procedencia de, tierras africanas, Berbería, cuya renta seguía, no obstante, comprendida en el almojarifazgo mayor de Sevilla. Intercambio 
mercantil del que se apartó expresamente a EI Puerto de Santa M aría, a buen seguro para evitar así el contrabando por un amarradero bajo titularidad señorial.

De este modo, las mayores dificultades para la recaudación de las tasas del comercio con el exterior tuvieron lugar en estos territorios ribereños de señorío, que abarcaban prácticamente toda la costa desde la frontera con Portugal hasta Gibraltar (mapa 1), debido a que estaban gobernados por una aristocracia presta a recaudar en su provecho los impuestos reales, incluso más allá de lo que le permitían los títulos de sus dominios patrimoniales. De este modo, una barrera de tierras bajo administración de poderosos nobles se interponía entre el mar y Sevilla, pues apenas algunos puntos del litoral pertenecían al realengo: la propia Sevilla, con acceso desde el Guadalquivir que era hasta allí navegable; Cádiz, a partir de 1493, cuando retornó a la Corona; y Jerez de la Frontera, también con acceso a través del Guadalete 0 desde sus playas, donde sería creado por los Reyes Católicos un nuevo enclave portuario con la fundación de Puerto Real, en 1483. A unque ni siquiera en estos escasos lugares bajo jurisdicción directa de la Corona los almojarifes sevillanos tenían garantizada su actuación y el cobro del impuesto. De todos modos, no hemos de olvidar que el mayor nivel de fraude y de oposición al cobro se dio en los señoríos costeros, donde sus titulares intentaron la percepción en provecho propio del gravamen arancelario, que en muchas ocasiones rebajaron por su cuenta para atraer a mayor número de mercaderes a sus atracaderos, en detrimento de otros fondeaderos cercanos o del puerto de Sevilla; una forma indirecta de contrabando, por tanto, potenciada desde instancias nobiliarias. Por ello, los órganos de gestión hacendística de la Corona acabaron por querellarse contra los titulares y lugares que impedían o dificultaban que los arrendatarios del almojarifazgo mayor de Sevilla recaudasen en sus costas el derecho del cargo y descargo de las mercancías, o tasa aduanera ${ }^{6}$.

${ }^{6}$ A GS, CC, Diversos, 9, 3; Ladero 1969, p. 88; 1982b, pp. 561-562. 


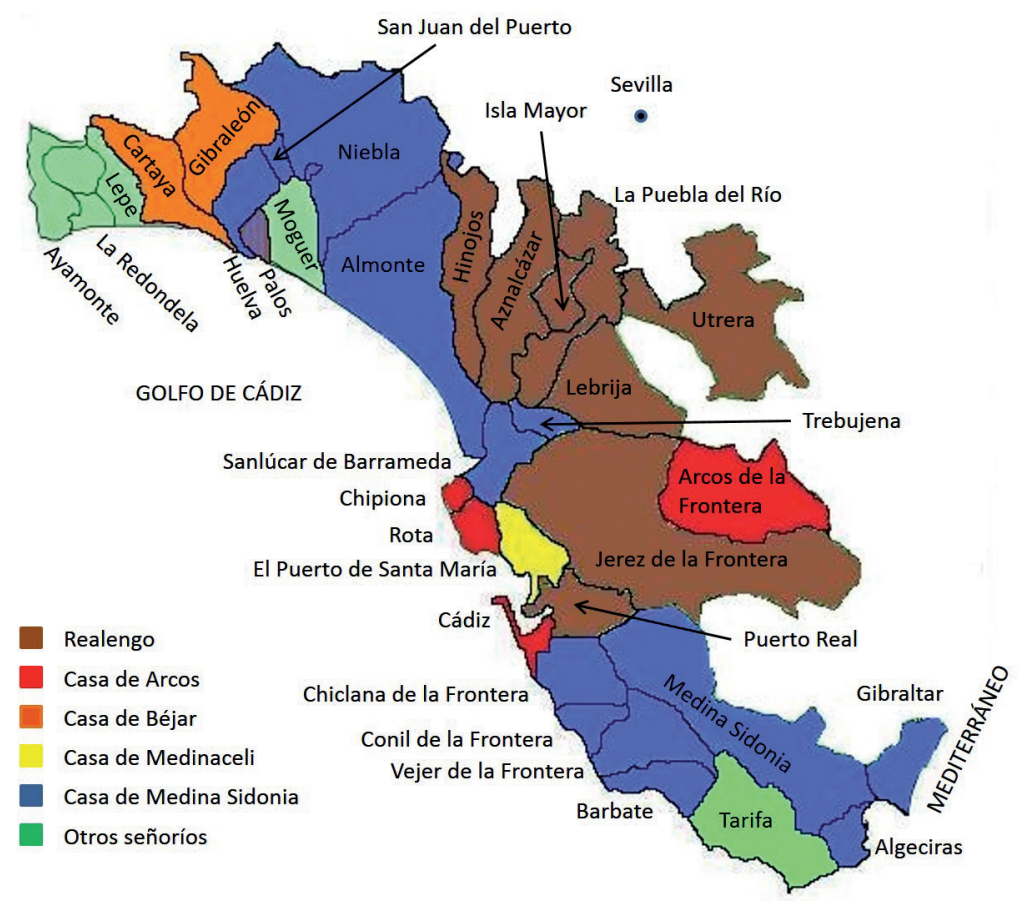

Fig. 1. Señoríos de la costa de la baja A ndalucía a finales del siglo XV.

En 1488, la reina Isabel hubo de remitir el mismo día dos cartas a todas las autoridades locales del arzobispado de Sevilla y obispado de Cádiz, para que consintiesen a los arrendatarios del almojarifazgo mayor de Sevilla, por cuatro años y hasta 1491, J uan de Haro, regidor de Ciudad Real, y Francisco de $M$ ena, vecino de A randa de Duero, que situasen en ellas a sus hacedores y guardas para que en su nombre recaudasen el tributo, pues se habían resistido a hacerlo poniendo excusas y dilaciones; tal es como que previamente habían de ordenarlo los respectivos señores territoriales o que no se tenía por uso y costumbre. L a monarca se apoyó para ello en una cláusula del cuaderno de 1450, que más abajo veremos, por el que se regía el arrendamiento de la renta, que recordaba cómo en muchos puertos, sobre todo de señorío, se introducían o sacaban mercancías de contrabando, por lo que se mandó que no se traficase por ellos sin licencia y albalá de los almojarifes, so pena de ser perdido el género como descaminado en favor de los arrendatarios; a los que si los señores territoriales impedían hacer efectiva dicha confiscación, deberían compensar pecuniariamente. El citado Haro solicitó igualmente de los Reyes 
Católicos, ese mismo año, una carta que contuviese la cláusula comprendida en otro cuaderno de 1450, el del partido de las mercaderías, que como sabemos generalmente estuvo unido con el resto del almojarifazgo, mediante la cual se obligaba a que de todos los paños llegados por mar a cualquier lugar del reino de Sevilla le abonasen a él la alcabala de la primera venta?.

Fueron acciones insuficientes que no acabaron con el alto nivel de fraude y contrabando, que ponía en riesgo la propia renta, ya que hasta los mercaderes embargados por no pagar el impuesto emprendían largos pleitos que dilataban la ejecución de las penas en las que incurrían. Por ello, Isabel I nombró para 1488-1489 al bachiller Francisco Ortiz como juez ejecutor encargado de entender en dichas causas, para agilizar los procesos judiciales; sobre cuyas sentencias no cabría apelación al guna, salvo ante los contadores mayores de la $\mathrm{H}$ acienda. A finales de 1491 las quejas de los nuevos arrendatarios del siguiente ejercicio iban dirigidas contra los concejos señoriales de la costa, así como contra al gunos poderosos caballeros sevillanos, de los que recelaban que cuando les reclamasen pagos relacionados con el arbitrio no les serían satisfechos. De manera que también solicitaron otro juez especial, que en esta ocasión fue el bachiller Lope Ruiz de A btillo, alcalde de la justicia de Sevillå.

Estas dificultades encontradas por los almojarifes sevillanos para recaudar la exacción en los lugares de señorío debieron de influir en el ánimo de los Reyes Católicos para encargar al licenciado Rodrigo de Coalla una pesquisa al respecto, en 1491; la cual se enmarca en una actuación más generalizada llevada a cabo por esas fechas para revisar la mayoría de las tasas exigidas a nivel local sobre el tráfico comercial en toda A ndalucía, algunos de cuyos ejemplos veremos a continuación. $L$ a antedicha pesquisa fue emprendida debido a que en los años anteriores habían sido abiertos sin licencia puertos de mar en Cádiz, Gibraltar, Sanlúcar de Barrameda, Puerto de Santa M aría, Palos, M oguer, Huelva, Vejer, Rota, Ayamonte, La R edondela y otras partes del arzobispado de Sevilla y obispado de Cádiz, en los que sus señores, sin disponer de títulos para ello, cobraban almojarifazgo, imposiciones y otros derechos de las mercancías que por ellos transitaban, en perjuicio del trato mercantil y del almojarifazgo mayor de Sevilla, que era el impuesto que debían abonar tales artículos comerciales ${ }^{9}$.

\footnotetext{
${ }^{7}$ González 2014.

${ }^{8}$ Carande, Carriazo 1968, vol. V, pp. 33-38; Fernández, Ostos, Pardo 1997, vol. VI, pp. 148-151.

${ }^{9}$ A GS, RGS, 1491-04, 79; Palenzuela, A znar 2010, p. 65.
} 


\subsection{C asa deArcos}

Si comenzamos el análisis de estas usurpaciones por la casa ducal de A rcos, los Ponce de L eón consiguieron poner bajo su control el almojarifazgo de Cádiz mientras esta ciudad estuvo bajo su jurisdicción, entre 1467 y 1493. Se trató de un puerto de importancia vital, sobre todo para el intercambio mercantil con Á frica, de ahí que en 1488 los almojarifes sevillanos Ilegasen a un acuerdo con los almojarifes gaditanos, al servicio del duque, para que los primeros emitiesen licencias gratuitas para que las mercancías con destino a Berbería pudiesen ser remitidas desde las plazas que no podían comerciar directamente con dicho continente, o puertos vedados, hasta el surgidero gaditano, donde sus almojarifes cobrarían el arancel y los sevillanos situarían a un factor que redactase nuevas licencias de salida, de las que obtendría 6 mrs. por cada una. L os citados puertos vedados serían los restantes de señorío, de la costa de la baja A ndalucía, no así el de Sevilla, que tendría trato directo con Á frica. Sin embargo, tras su incorporación al realengo, a partir de 1493, Cádiz sí monopolizó todo el tráfico con B erbería, como ya he dicho, aunque las tarifas arancelarias demandadas sobre el mismo seguían comprendidas dentro del almojarifazgo mayor de Sevilla. M ientras, el resto del almojarifazgo gaditano, exigido sobre las mercancías no traficadas con Á frica, quedó incluido en el partido de J erez. Hasta 1495, cuando el propio almojarifazgo xericense, como también por tanto el gaditano, fueron agregados al mayor de Sevilla que, a partir de 1498, englobó además los restantes almojarifazgos costeros; junto a los del reino de Sevilla, los de los de G ranada y M urcia. Sin embargo, parece ser que ya desde cuatro años antes de la muerte del duque, esto es, al menos desde 1488, los almojarifes sevillanos percibían el almojarifazgo de Cádiz.

Se han conservado unas cuentas de las rentas ducales de la localidad entre 1485-1486, provenientes, sobre todo, del citado almojarifazgo, que llegó a sumar en torno al medio millón de maravedís anuales, y de las alcabal as, ambas exacciones en teoría de titularidad real. A este respecto, fue suscrito entre 1488 y 1490 otro acuerdo entre los al mojarifes de Sevilla y los que cobraban el almojarifazgo gaditano. Éstos podían dar permisos para cargar libremente en el embarcadero productos con destino a Sevilla, así como al por menor hacia J erez, Sanlúcar de Barrameda, Puerto de Santamaría y otros lugares cuyos vecinos gozasen de las mismas franquezas que los gaditanos, esto es, exención de almojarifazgo de los suministros para su abastecimiento; si bien debían entregar a los primeros relación detallada de las licencias de embarque emitidas. L os derechos de las mercancías vendidas en Cádiz y su bahía serían para sus almojarifes, pero, como he expuesto más arriba, probablemente los exigi dos sobre los restantes bienes allí descargados con destino a otros lugares irían a parar a los almojarifes sevillanos. Q uienes, además, podían poner en el 
lugar guardas y barquetas de vigilancia, que no fiscalizarían, no obstante, la flota de galeras venecianas arribada cada año. La justicia gaditana atendería los litigios sobre el cobro del impuesto, pero según el cuaderno real de arrendamiento. En el surgidero también se podían cargar los productos originarios de otros señoríos de la costa atlántica andaluza. El comercio con Berbería tendría, asimismo, origen y destino en este amarradero, y tributaría a los almojarifes gaditanos, aunque las licencias serían otorgadas por un delegado de los sevillanos.

A demás, los Ponce de L eón habían conseguido de Enrique IV, como otros señores con puertos atlánticos, el cobro de una tasa del $1 \%$ sobre el cargo y descargo de mercaderías, para lo que podían colocar sus factores tanto en la propia Cádiz como en Jerez, porque, como sabemos, la primera era el antepuerto de la segunda, donde se descargaban las mercancías luego allí llevadas en barca por el Guadalete, y viceversa. EI documento fue expedido en 1472, y confirmado por los Reyes Católicos en 1476 y 1478, aunque en este último caso, debido a la queja del concejo xericense, revocaron esta tasa de lo descargado-cargado con destino a Jerez. Si bien fue nuevamente exigida en 1490, como lo reflejan las nuevas protestas de dicho consistorio, porque se le exigía en el puerto de Cádiz y en su bahía, lo que motivó una carta en la que los monarcas prohibieron al aristócrata seguir demandándola, y no solo a los jerezanos sino también a todos los súbditos castellanos, puesto que era contraria a derecho. Final mente resultó total mente suprimida en 1492, una vez muerto el duque Rodrigo, pues, según los soberanos, le había sido concedida como ayuda en la guerra contra Granada, que ya había finalizado ${ }^{10}$.

Según lo expuesto, en materia de mercedes y cesión de regalías, las cosas comenzaron a cambiar a partir de 1478, cuando los Reyes Católicos, consolidados en el trono tras varios años de guerras civiles, se sintieron con

${ }^{10}$ J unto a la tasa del $1 \%$, el duque demandaba en 1490 en la bahía de Cádiz al cabala de las mercancías adquiridas en las gal eazas y no descargadas, y de las que en ellas vendían los vecinos de J erez, en contra de la costumbre, porque los mares del reino eran libres. L os monarcas encargaron una pesquisa al respecto. Fallecido Rodrigo, los Reyes Católicos negociaron en 1493 con su viuda para que la ciudad retornase al realengo, de modo que a comienzos de ese año ordenaron que fuesen arrendadas para la hacienda regia sus rentas, entre ellas las al cabalas y el almojarifazgo, excepto el derecho ducal de carga y descarga del 1\% que ya no debería volver a cobrarse. En 1498, cuando, como he dicho, todos los almojarifazgos costeros del sur peninsular fueron incluidos en el mayor de Sevilla, no se encontraba entre ellos el maravedí del cargo y descargo que cobraba el duque de Arcos, es de suponer que era el antiguamente demandado en Cádiz, ni otros derechos de Sevilla u otras partes. De todas formas, al parecer los al mojarifes reales consiguieron hacer reaparecer la tasa señorial, que cobraban en su provecho, tal y como se desprende de un informe el evado a la Hacienda R egia en 1502. A HN, SN, O suna, carpeta 80, doc. 11; A GS, CC, Diversos, 4, 106; A GS, PR, LC, 17, ff. 106-107; A GS, RGS, 1476-04, 204; 1478-03, 53; 1492-10, 35; 1493-02, 16; A M JF, A C 1490, ff. 197r, 246r, 249r252r; 1491, f. 8r; 1492, ff. 240v-241r; Ladero 1974, pp. 85-95, 115-118; 1982b, p. 562; 1998, pp. 457-466, 482-485; A znar, Palenzuela 2009, pp. 674-675; González 2014. 
fuerzas para recortar las amplias ventajas en el ámbito fiscal obtenidas por el duque de Arcos, uno de sus aliados iniciales. M ediante una carta de 1490 ordenaron una pesquisa en las localidades de sus señoríos, la propia Cádiz, A rcos de la Frontera, Rota, Chipiona y Bailén, para comprobar si en ellas se exigían derechos indebidos sobre el tráfico mercantil (portazgos, rodas, almojarifazgos, castillerías...), según lo dispuesto en las Cortes de 1480; algo que también mandaron por esas mismas fechas en otras partes de A ndalucía. Tras la ampliación temporal de esta inspección sobre las aduanas, portazgos, almojarifazgo y otras imposiciones de los lugares antedichos, los monarcas ordenaron que en ellos no se continuasen cobrando tasas contrarias a la ley. A Igo que debieron repetir al año siguiente, 1491. M ientras, dispusieron que se suspendiese tanto en Rota como en Chipiona el cobro de almojarifazgo, portazgo u otras exacciones en tanto no se presentaban los títul os que facultaban al duque Rodrigo para percibirlos; cosa que no pudo hacer, aunque sí con arreglo a su villa de Arcos, según consta en un documento de 1495 dirigido a su nieto. Ese mismo año 1491 los soberanos se hicieron eco de la queja de los arrendatarios del almojarifazgo de Sevilla en el sentido de que en muchos lugares no les dejaban poner sus lugartenientes, guardas y naves con los que recaudarlo o vigilar su cobro, o los patrones de los barcos no les consentían subir a bordo para fiscalizar los cargamentos. Y ello en contra de los cuadernos de la renta dados por Juan II, que establecían la potestad de los almojarifes para situar vigilantes en el puerto de Cádiz, que debían estar presentes en el desembarque de las mercancías; prueba de que una cosa era la norma teórica recogida en la letra de la ley y otra la aplicación de la misma, que dependía en gran medida del poder efectivo de la monarquía en cada momento.

En 1492, Isabel y Fernando encomendaron una nueva pesquisa en los mismos términos que la vista del año anterior, encargada a Coalla, pero en esta ocasión en la persona del licenciado Sebastián de B alboa, miembro del Consejo de la Hermandad. Como en aquella, debía visitar las costas desde la frontera de Portugal hasta Gibraltar y averiguar si los señores de tal es lugares cobraban contra derecho tasas a los barcos que allí arribaban a cargar y descargar sus mercancías. Tras acudir a Rota y Chipiona, realizó interrogatorios sobre el embarque y desembarque de productos, de qué clase eran, por quién se hacían, natural es o extranjeros, de la provincia o de fuera, con qué licencia y, si no la tenían, si se debían tomar por descaminados por los almojarifes sevillanos; así como qué derechos se exigían sobre ellos, con qué facultad, y si esto era consentido por dichos almojarifes, o si éstos tenían allí a sus factores o les habían dado facultad para ello; o si los mismos habían cobrado en tal lugar con anterioridad el almojarifazgo con autorización real, con qué diligencias y con qué guardas puestos para tal fin, o si tenían barquetas para vigilar el tráfico marítimo o inspectores que registrasen el género. Seguida- 
mente, tanto el duque como sus villas fueron emplazados por el procurador fiscal real y comenzó un pleito ante el Consejo R eal y los contadores mayores que fue fallado en favor del segundo, pues se halló que el derecho de cargo y descargo de la mar de dichos puertos pertenecía a la Corona y a sus arrendatarios, a los que no se podía impedir cobrarlo y ubicar allí a sus guardias y factores. A demás, como el puerto de Chipiona había sido abierto sin licencia de los soberanos, se reservaban la posibilidad de que ordenasen su clausura 0 dejarlo fuera de servicio. En su defensa, el señor de A rcos alegó que tanto él como sus antepasados habían percibido el almojarifazgo en sus villas sin la oposición de los al mojarifes sevillanos, y que los vecinos de éstas eran francos de abonarlo por los artículos de su labranza y crianza. La respuesta del procurador fiscal fue que, ya en tiempos de J uan II, se había establecido mediante pragmática real que el cargo y descargo no entraba entre los derechos donados a los señores, tras otra que establecía que aquéllos que gozasen de títulos para recaudar rentas reales presentasen los documentos que los facultasen y, si en un año no lo hacían, éstos serían revocados y carecerían de valor. Del mismo modo, los reyes regularon las tasas que sí eran conformes a derecho con el fin de que no se exigiesen mayores aranceles que los debidos, para lo que promulgaron nuevos padrones de portazgo para al gunos lugares patrimoniales de los Ponce de León, caso de la fortal eza de la M onclova, sita en Fuentes de A ndalucía, M airena (del A Icor), Olvera, M orón, A rahal y B ailén.

En 1493, Ios monarcas urgieron al pesquisidor Sebastián de Balboa para que terminase la averiguación, pues la nueva titular del señorío, la duquesa viuda, B eatriz Pacheco, había denunciado a los almojarifes reales por cobrar el impuesto en ambas localidades sin que hubiese culminado aquélla. La enfermedad y muerte del señor habían paralizado la inspección, de modo que en 1495 los soberanos nombraron para continuarla al escribano de cámara Gonzalo de Córdoba.

En 1503 se fecha la ejecutoria mediante la que I sabel y Fernando pusieron fin al litigio con el duque de Arcos, iniciado en tiempos de Rodrigo Ponce de León, y los concejos de sus villas. Pero no terminaron ahí del todo los debates, que se reiniciaron hacia 1516, por lo que la reina J uana se vio obligada a emitir una sobrecarta que recogía la ejecutoria dada por sus padres más la carta de 1491 sobre la vigilancia de las costas por los almojarifes, que vimos al hablar del caso de Cádiz, que mandó pregonar en las antedichas localidades. Con todo ello, la monarquía desbarató el intento de los señores de A rcos y $M$ archena por crear un almojarifazgo propio, al margen de la hacienda regia, al estilo del que poseían sus enemigos de Medina Sidonia en su puerto de Sanlúcar de Barrameda, lo que hubiese supuesto una gran sangría para las arcas reales en materia fiscal, aparte del margen de contrabando que posibilitaba. De ahí el esfuerzo de los R eyes Católicos por retornar Cádiz 
a la Corona; además, lograron que resultasen infructuosos los intentos de dicha casa por retener los al mojarifazgos de Rota y Chipiona. Se trató del inicio de una política de eliminación de tales gravámenes así como de recuperación para la $\mathrm{H}$ acienda de los impuestos aduaneros usurpados por la aristocracia ${ }^{11}$.

\subsection{C asa de M edinaceli}

Por lo que respecta a los M edinaceli, gracias a la gran cantidad de ventajas y exenciones fiscales obtenidas por su villa de EI Puerto de Santa M aría en el siglo XIII, la localidad mantuvo hasta bien entrado el XVI una situación privilegiada en esta materia. De este modo, al parecer los titulares del señorío, los de la Cerda, habrían llegado a algún tipo de pacto con la monarquía, similar al de Cádiz y los Ponce de León, para que los almojarifes no pudiesen actuar en el interior de la población, si bien no dejaban por ello de percibir el impuesto aduanero, del que les harían entrega por tanto los agentes señoriales, los almojarifes del duque o los arrendatarios de sus rentas, con el nivel de fraude que ello entrañaba.

En 1485, los jerezanos reclamaron en EI Puerto exención de tasas por el trasbordo de mercancías de un navío a otro, siempre que se hiciese en el río Guadal ete, y no en tierra, y sin que hubiese venta al guna. También pretendían poder comprar y vender libre y francamente, y sin dar razón alguna, todo tipo de cosas por parte de los vecinos de la ciudad o que fuesen para ellos. El señor lo denominó como rrío propio mío asy como las otras cosas e términos que son desta villa, por lo que contestó que, por ser un curso de agua de su propiedad, los xericenses debían allí pagar al cabala de sus compraventas. Por su parte, el consistorio de J erez respondió que todos sus habitantes, así como los comerciantes que de ellos compraban, vendían, cargaban y descargaban sus productos en los mares, ríos y puertos salados de toda la comarca estaban libres de abonar gravámenes y de comunicar esta circunstancias a ningún recaudador, tal y como siempre se usó. De manera que denunció ante los Reyes Católicos y el duque que su villa exigía nuevos cánones contrarios a derecho.

En 1488, el antes citado J uan de Haro, arrendatario mayor del almojarifazgo hispalense, hizo pregonar en dicha ciudad el mencionado cuaderno

${ }^{11}$ A GS, PR, leg. 36, 18; leg. 59, 83 ; A GS, PR, LC 3, ff. 28-43; 17, ff. 113-115 ; A GS, CC, Diversos, 3, 84; AGS, RGS, 1490-06, 143; 1490-07, 128; 1490-08, 43; 1490-10, 54-57, 59; 1491-08, 230; 1495-04, 27; 1492-06, 153; A H N, SN, O suna, carpeta 75, docs. 10-11; caja 183, docs. 49, 62. En 1502 en el al mojarifazgo mayor de Sevilla se incluían todos los restantes costeros, sin embargo el de Rota y Chipiona se habría arrendado aparte, tal vez porque no se había fallado todavía el pleito más arriba visto. Ese año recayó en García del Castillo, por un importe de 45.000 mrs.; A znar, Palenzuela 2009, pp. 676, 688. 
de su recaudación del año 1450, que prohibía el embarque y desembarque de mercancías en todos los puertos del reino de Sevilla sin su autorización, y que lo facultaba para poner guardas y hacedores en cualquiera de ellos; de forma que tendría por descaminadas las que no abonasen el arancel. Puede que fuese el inicio de un largo proceso judicial al respecto que culminó a mediados del siglo XVI, entre los almojarifes y el concejo portuense. U na primera sentencia del año siguiente, 1489, condenaba en rebeldía a EI Puerto porque no se había personado en la causa, y concedía todos los derechos sobre el cargo y descargo de la mar del lugar a los almojarifes sevillanos. A lgo similar a lo que por esas fechas, al parecer, ocurrió en Sanlúcar de Barrameda. Por su parte, el consistorio se amparó en una carta remitida por los R eyes Católicos a los arrendatarios Francisco de $\mathrm{M}$ ena y Juan de Haro, que les mandaba que en esa localidad no se aplicasen las nuevas normativas de cobro del impuesto, sino que se recaudase como siempre hasta que los monarcas dispusiesen lo contrario.

Este estado de cosas se mantuvo hasta 1492, cuando los soberanos ratificaron este derecho al duque de por vida, e impidieron a los almojarifes poner barquetas de vigilancia en el fondeadero, también hasta que falleciese su señor 0 al menos por 10 años. EI noble aleccionó a su contador y al alcaide portuense sobre cómo debían negociar con la reina y los almojarifes a este respecto: si bien se mantenía en la negativa de que los antedichos entrasen en la población, si finalmente lo conseguían, no deberían exigir cosa al guna sobre las cosechas y pescado de los vecinos, que en todo caso corresponderían a los arrendatarios de las rentas ducales. Tampoco era conveniente que aquéllos conocieran a cuánto ascendía la recaudación anual aduanera, sin duda para mantener los márgenes fraude. $L$ as cuentas debían asentarse en sus propios libros contables de las rentas ducales, a partir de los cuales los al mojarifes percibirían su parte, para así dejar patente el derecho señorial sobre la gabela. Pedía, igual mente, que se intentase que las mercancías transportadas en galeazas quedasen exentas. Por último, la quinta parte de lo defraudado aprehendido en lugar de ir al rey debía quedarse en la villa, para pagar la barqueta de vigilancia, o en su defecto el quinto de lo confiscado en la renta de Berbería.

A partir de entonces menudearon los conflictos entre el regidor J uan Gómez Cantalapiedra, procurador síndico del consistorio, y los guardas y factores de los almojarifes. A sí, por ejemplo, en 1496 el alcaide de El Puerto, Charles de Valera, se quejó ante el concejo de Jerez porque el factor de los almojarifes sevillanos en esa ciudad, Rodrigo Bazo, que debía de ser hermano del que ejerció como tal hasta poco tiempo antes, Gonzalo Bazo, cobraba en ambas localidades derechos excesivos. El hacedor respondió que estaba facultado para hacerlo por el cuaderno de recaudación redactado por los Reyes Católicos; que el consistorio encargó estudiar a una comisión para que le 
informase al respecto. Todo ello llevó a los monarcas a encargar pesquisas al respecto $y$, en 1500, a emplazar al concejo portuense.

En 1502, tras la muerte del primer duque, Luis de la Cerda y M endoza, se dio una primera sentencia que atribuía los derechos de cargo y descargo a la Corona, y facultaba a los arrendatarios del almojarifazgo a entrar en la villa, poner vigilantes, barquetas y hacedores. No obstante, los vecinos podían embarcar francamente los productos de su labranza y crianza, con el margen de contrabando que ello permitía. No contento con ello, el nuevo duque Juan apeló, pues pretendía exención asimismo para el equipamiento de los barcos pesqueros, los paños y otras mercancías; que no le fue concedida hasta que no se diese sentencia definitiva. Esta situación se mantuvo en suspenso hasta la década de 1530, cuando la causa Ilegó a la Chancillería de Granada. Por fin, en 1541 la ejecutoria del pleito eximía a los portuenses de almojarifazgo del pescado fresco o salado, no en escabeche, sal y vino. Si bien la exacción la siguieron recaudando a partir de entonces los duques que, a través de sus representantes, firmaban acuerdos con los al mojarifes sevillanos para entregarles la parte que les correspondía. Previamente, durante el intervalo en el que no controlaron la recaudación de forma directa, entre 1502 y 1541, el interés de los de la Cerda por el canon aduanero fue tal que suscribieron acuerdos casi secretos con los arrendatarios para subarrendar su cobro en su fondeadero portuense, como los fechados en 1512 y 1516 . El primero supuso la cesión al duque por los almojarifes sevillanos de 7/12 del impuesto cobrado en EI Puerto, sin la renta de B erbería, a cambio de medio millón de maravedís. Los problemas Ilegaron cuando sus contadores pretendieron a partir de 1515 percibirlo todo, lo que llevó a un nuevo contrato al año siguiente, en el que los ahora 5/12 subarrendados a Pedro de Santa Cruz alcanzaban un precio de 330.000 mrs., cuando el almojarifazgo mayor fue valorado en casi 16,6 millones, si bien el antedicho arrendatario recibió un premio personal por parte del señor consistente en 50.000 mrs., más otros 30.000 por razón de ciertos gastos. Esta generosidad y el evidenteinterés del II duquesobreel arancel nos hablan de varias cosas. A demás de un intento de aminorar los daños económicos y jurisdiccionales sufridos, también buscaría hacerlo con el prestigio perdido frente a sus competidores, los M edina Sidonia, que sí mantenían sus derechos en el almojarifazgo de Sanlúcar. A partir de 1517 estos acuerdos fueron más complicados porque el tributo fue encabezado por el concejo de Sevilla ${ }^{12}$.

Hacia 1464 el concejo del Puerto de Santa M aría impuso un nuevo tributo sobre los navíos que recalaban en su surgidero en forma de anclaje,

${ }_{12}$ A GS, PR, leg. 36, 26; PR, LC, 3, ff. 9-11; AGS, RGS, 1492-10, 4; AMJF, AC 1496, ff. 33v-34r; R omero 2009; Salas 2014; G onzález 2014. 
que era contrario a derecho por no haberse demandado con anterioridad. En 1483 se estableció también que ningún barco podía entrar en su fondeadero si no era pilotado por un lemán local, amén de abonar el correspondiente pilotaje; otra novedad consistió en una renta que se cobraba a los que pasasen por el río Guadalete. Contra ello protestó el concejo de Jerez ante el duque de M edinaceli. Posteriormente, ese mismo año se suscribió un acuerdo entre El Puerto y Jerez por el cual el uso del piloto por las embarcaciones se hacía opcional, mientras que la tasa que éste cobraría seguiría siendo la de siempre. Lo que no impidió que la primera villa continuase con la exigencia de 1 dobla castellana por cada buque, otra de monte (atracar en el muelle fluvial), y otra de anclaje y pilotaje, amén de otros derechos cobrados por el almirante, asimismo contrarios a los privilegios de J erez, tal y como expusieron al gunos maestres vizcaínos con naves ancladas en dicho surgidero. Todo ello motivó la intervención en 1484 de los R eyes Católicos, que solicitaron del señor local que evitase estos desmanes cometidos por el ayuntamiento portuense. También mandaron al alcalde J uan de la Fuente que investigase si el concejo de la villa exigía nuevas imposiciones y derechos a los navíos que llegaban a dicho amarradero, en contra de las leyes y de los acuerdos tomados en las recientes Cortes de Toledo de 1480. Todavía en 1489 continuaban los desmanes, tal y como denunció un vecino de Jerez, cuya nave fue retenida por no ponerla a monte y no pagar por ello el servicio de 1 dobla destinado al duque, como hacían el resto de los maestres forasteros, pero que él no debía satisfacer por ser jerezano. Para entender en el asunto, tras remitir dos misivas al Puerto sin resultados, se comisionó a un veinticuatro y a un jurado xericenses, e incluso se amenazó con tomar represalias. El enviado portuense respondió que dicha tasa la venían cobrando los de $L$ a Cerda desde hacía más de 70 años, por concesión real, aunque solo de los forasteros, no de sus vecinos ni de los jerezanos ${ }^{13}$.

\subsection{C asa de M edina Sidonia}

En cuanto a los M edina Sidonia, su villa de Sanlúcar de Barrameda, sita en la desembocadura del Guadal quivir, fue, junto a Cádiz, la única excepción señorial legal al monopolio del cobro de impuestos aduaneros comprendidos en el almojarifazgo mayor de Sevilla, pues, como he dicho, contó con uno propio perteneciente a dicha casa, al parecer concedido por Sancho IV a Guzmán el Bueno, al que diera el cargo y el descargo de la mar junto con la

${ }^{13}$ A M JF, A C 1464, ff. 129r, 135r; 1483, ff. 17r-v, 181r, 226v; 1484, f. 172v; 1485, f. 150r-v; 1489, ff. 60r, 73r, 101r-v, 122r. 
villa; luego confirmado por una declaratoria real de A Ifonso XI (1327), a raíz de un pleito del titular de la plaza, J uan A Ifonso de Guzmán, segundo señor del lugar, contra los almojarifes sevillanos; posteriormente ratificada por Pedro I (1351). Éstos pretendían que les pertenecía el almojarifazgo a abonar por las mercancías que los barcos cargasen y descargasen en el puerto de la Hoz del canal de Barrameda, operaciones que no se podían realizar sin su licencia; mientras que el noble alegó que dicha renta le había sido dada junto con la viIla; a lo que los primeros replicaron que le fue concedida la localidad pero no su embarcadero. El rey determinó que el citado al mojarifazgo pertenecía a los Guzmanes y no a la hacienda regia, por lo que se debía descontar su importe a los arrendatarios que en ese momento lo tenían. En 1460 Enrique IV confirmó al I duque esta merced en agradecimiento a la pacificación de Sevilla, documento del que se desprende que años antes el almojarifazgo pudo haber retornado a la Corona y que alude a un privilegio de J uan II por el que habría concedido al conde de Niebla dichos derechos. Posteriormente, en 1464 Enrique IV ratificó a J uan de Guzmán, duque de M edina Sidonia y conde de Niebla, sus privilegios para que a través de los puertos de sus villas de Sanlúcar de B arrameda, L epe, Huelva, Ayamonte y La Redondela se pudiese comerciar libremente. M ás adelante, en 1469 dispuso que los arrendatarios del almojarifazgo de Sevilla no pudiesen cobrar allí cosa alguna por el cargo y descargo de las mercancías; mientras que, de forma explícita, reafirmó que dicho derecho pertenecía a su señor en Sanlúcar de Barrameda, que en ese momento era Enrique de Guzmán, hijo del anterior. U na nueva confirmación fue emitida en 1470, en la cual se recogen los privilegios precedentes, desde 1327. Y esta no fue la última, debido a la presión que ejercían los al mojarifes sevillanos que querían hacerse con el cobro del impuesto en Sanlúcar, por lo que en 15121513 Fernando el Católico, a petición del IV duque, emitió una cédula en la que les ordenaba respetar los derechos señoriales, en contra de lo dispuesto años antes por su hija J uana I para que dichos almojarifes recaudasen todos los derechos de las mercancías que transitasen por dicho puerto. Estos últimos advirtieron al rey Fernando del peligro de mantener el agujero fiscal en que se había convertido este surgidero, en el que se estibaban y desestibaban gran cantidad de artículos con destino a Sevilla, de la que actuaba como antepuerto. Pero la situación solo se vio corregida en parte cuando en 1522 Carlos I impuso un nuevo canon conocido como la avería del uno por ciento sobre todas las mercancías que por allí pasasen ${ }^{14}$.

${ }^{14}$ Entre 1509-1511 el cobro de esta exacción rentó a los duques unos 1,6-1,8 millones de maravedís anuales, cantidad con la suficiente envergadura como para explicar los frecuentes litigios entre los almojarifes sevillanos y los señores de la villa, y que permite pensar que los primeros estuviesen al entados desde la propia Corona, para recuperar por esta vía el control 
No sabemos en qué condiciones y con qué tarifa se cobraba este tributo, pero todo parece indicar, en contra de lo que se pudiera pensar por ser una renta señorial, que las tasas exigidas eran inferiores a las demandadas en Sevilla, en su almojarifazgo mayor de titularidad real. Ello atendió a una estrategia de los duques para competir deslealmente con los puertos de realengo y atraer así mayor número de embarques y desembarques, y, con ellos, una más elevada recaudación a pesar de la rebaja arancelaria; de este modo se prentendía que Sanlúcar se convirtiese en un auténtico antepuerto de Sevilla, donde incluso se descargasen mercancías con destino a dicha ciudad gracias al atractivo de las rebajas fiscales y a que los barcos de gran calado no podían remontar el Guadal quivir hasta el puerto de la capital andaluza. Prueba de este dumping la encontramos en que los titulares de esta villa habían concedido a los mercaderes bretones exención para todos los productos que introdujesen o sacasen de ella. A lgo que en 1468 dicha comunidad mercantil solicitó del concejo de J erez que le fuese también allí otorgado ${ }^{15}$.

Este estado de cosas empezó a cambiar, salvo para Sanlúcar, con la Ilegada al trono de Isabel I. No obstante, los almojarifes sevillanos no se resistieron a intentar exigir también el almojarifazgo real en dicha plaza. Así, en 1491 un mercader genovés se quejó ante los Reyes Católicos porque le fueron embargados por sus guardas, que patrullaban en barquetas, una serie de paños que pretendía sacar del lugar en un barco, tras pagar allí los derechos correspondientes; para lo que los arrendatarios hispalenses al egaron que no les había pedido licencia ni pagado a ellos la exacción, según el nuevo arancel del impuesto recientemente emitido. Los monarcas dispusieron que restituyesen lo requisado, aunque se dio inicio a un proceso judicial. Ese mismo año, el duque y sus concejos de Huelva y San J uan del Puerto protestaron contra la decisión de un juez comisario que había fallado en favor de los al mojarifes sevillanos ${ }^{16}$.

En torno a 1503 se vio un pleito por el Consejo R eal y los Contadores $M$ ayores emprendido por el procurador fiscal real, de una parte, contra J uan de Guzmán (J uan A lonso Pérez de Guzmán y de Ribera), (III) duque de M edina Sidonia, y contra el consistorio y los vecinos de su villa de N iebla, de la otra. El motivo era que muchos caballeros y concejos no consentían a los arrendatarios reales cobrar en sus términos el almojarifazgo. En este sentido, se recoge la carta del año 1492, vista más arriba para R ota y Chipiona, que dio lugar a la pesquisa del licenciado Sebastián de B alboa, miembro del Consejo de la

fiscal sobre este valioso enclave portuario: A GS, M S, leg. 3, 37; leg. 5, 84; A HN, SN, O suna, caja 35, docs. 111-112; L adero 1969, p. 88; 1974, p. 93; 1982b, p. 564; 2012, pp. 1492-1495; Moreno 1983, pp. 78, 198-200.

${ }^{15}$ A M JF, A C, 1468, f. 135r; N avarro 1988, p. 334-335.

${ }^{16}$ A GS, RGS, 1491-06, 68, 99; 1491-10, 29, 112. 
Hermandad, quien acudió a Niebla, donde recabó información sobre el desembarco de mercancías en los mismos términos que en las antedichas localidades. Tras ello, el duque y la villa fueron emplazados por el procurador fiscal y alegaron en su defensa que de la antedicha pesquisa se desprendía que tanto los vecinos como los forasteros que allí llevasen sus productos, lo mismo por mar como por tierra, estaban exentos de abonar gravamen alguno, tampoco al mojarifazgo, desde hacía más de 100 años, sin dunda gracias al privilegio de exención de portazgo concedido en el siglo XIII; con consentimiento, tanto de los reyes como de los almojarifes de los tiempos pasados. A demás, el aristócrata añadió que si en al gún momento los almojarifes habían puesto barquetas en dicho puerto había sido sin su conocimiento, y que había recibido de la monarquía la donación de la villa con sus pechos y derechos, especialmente el almojarifazgo de la mar y de tierra, con sentencia a su favor emitida por el Consejo Real del rey Alfonso (¿XI?). El dictamen del Consejo Real de los monarcas católicos en el pleito del almojarifazgo del cargo y descargo de la mar en los puertos fluviales del Río Tinto del Portichuelo, Vado de M artín Juárez y M olinillo, en término de N iebla, fue favorable al procurador fiscal, de modo que el citado canon pertenecía a la Corona, y el duque ni sus intercesores no debían perturbar su cobro a los arrendatarios del almojarifazgo mayor de Sevilla. El gravamen debían satisfacerlo en el citado lugar así los vecinos como los foráneos, tanto de los artículos de su labranza como por cual esquier otros. Contra este fallo apeló el noble, quien dijo que en el documento que lo facultaba a él y a sus antecesores para recibir los derechos de su señorío se hacía mención al almojarifazgo, por lo que se debía entender que comprendía éste el cargo y descargo de la mar, según la antedicha resolución de tiempos alfonsíes; además, los vecinos de Niebla nunca habían pagado almojarifazgo por los bienes de su labranza y crianza. Por su parte, el procurador fiscal alegó lo mismo que en el pleito de Rota y Chipiona. Finalmente, el veredicto definitivo ratificó el anterior en favor de los almojarifes y de la Hacienda regia ${ }^{17}$.

En términos parecidos transcurrieron los litigios sobre otros fondeaderos de los M edina Sidonia. Los de Huelva y San J uan del Puerto, segregado de Huelva en 1468 por el duque para fundar un atracadero en la ribera derecha del Río Tinto que compitiese con los de Palos y M oguer, sitos en la margen izquierda, culminaron en 1504, pero, como en el caso de los de la casa de A rcos, precisaron de la redacción de sobrecartas reales en 1516 para ratificar las sentencias. Este último embarcadero, como vimos con Chipiona, carecía de licencia de apertura y podía ser clausurado por la Corona ${ }^{18}$. En Palos,

${ }^{17}$ A GS, PR, leg. 36, 14. PR, LC, 3, ff. 9-11; PR, LC, 17, ff. 115-117.

${ }^{18}$ A GS, PR, leg. 36, 15; PR, LC, 3, ff. 44-61; PR, LC, 17, ff. 118-120. 
perteneciente a los condes de M iranda y Cifuentes ( $y$, a partir de 1480, una parte a los M edina Sidonia, y desde 1492, otra a la Corona), sus vecinos se resistieron a satisfacer el arancel aduanero hacia 1512, alegando estar exentos, de modo que la reina J uana les remitió también en 1516 los documentos más arriba vistos de tiempos de J uan II y sus padres, que les obligaban a hacerlo ${ }^{19}$.

Ese año 1504 fue pedido a los alcaldes de Conil (Torre de Guzmán), por J uan de Sevilla, factor de los almojarifes sevillanos, que se cumpliese una carta ejecutoria de los Reyes Católicos, así como otra misiva de los monarcas, fechada el año anterior, 1503, y se le permitiese recaudar allí, así como en Chiclana y Vejer, el impuesto. En la segunda, los soberanos manifestaban que los arrendatarios del almojarifazgo mayor de Sevilla se les habían quejado por el dinero que les era debido en diversas villas de dicho impuesto, lo que no podían demandar ante las justicias locales porque eran lugares de señorío y sus componentes, parientes y amigos de los deudores, por lo que no serían debidamente atendidos. A nte esta circunstancia los soberanos habían situado como juez imparcial en el asunto a uno de Sevilla, el licenciado M ateo Vázquez de Á vila. Por su parte, la citada ejecutoria entregada en las antedichas villas a petición de Pedro de M ayorga, representante de los al mojarifes Francisco Ortiz, Rodrigo de M edina y de sus consortes, fue redactada en términos similares a las arriba referidas ${ }^{20}$.

\subsection{C asa de Béjar}

Por último, hay que hacer mención a la casa de Béjar, al duque Á Ivaro de Zúñiga y Pérez de Guzmán, y a sus villas de Gibraleón, Cartaya y San Miguel de Arca de Buey, segregada en 1458, donde se vivieron situaciones parecidas a las arriba descritas.

En 1445 los concejos de Gibraleón y Huelva suscribieron un convenio suscitado tras las quejas de los maestres de barcos arribados a dichas villas, que protestaban porque sus respectivos almojarifes les demandaban diversos tributos, anclajes y aduanas, de las mercancías allí estibadas y desestibadas, los cuales les eran exigidos cuando sus naves estaban fondeadas en el río O diel, que separaba ambas localidades, en contra de la costumbre. Concretamente, los miembros de sendos concejos se reunieron en noviembre del mencionado año en los mojones que separaban sus respectivos términos municipales para redactar el acuerdo. En él se recoge que dicho río era navega-

${ }^{19}$ A GS, PR, leg. 36, 19; PR, LC, 3, ff. 62-71.

${ }^{20} \mathrm{~A} G S, \mathrm{MS}$, leg. $3,44$. 
ble hasta la villa de Gibraleón, hasta el pozo de las naos conocido como del A renilla, declarándose el curso de agua público y abierto a todo tipo de embarcaciones, que allí podían anclar y fondear, así como cargar y descargar sus productos sin pagar contribución alguna, ya que tradicionalmente había sido exento como si fuese la mar braua ${ }^{21}$.

En 1501, el acalde mayor de San Juan del Puerto denunció ante los Reyes Católicos que en la vecina Gibraleón se llevaba indebidamente de portazgo el $2 \%$ por algunas mercancías, y el 2,5 por otras, de manera que los monarcas encargaron una investigación sobre el particular a J uan de Baeza. En su sentencia, este juez-pesquisidor determinó que el duque no podía demandar el $5 \%$ en concepto de almojarifazgo por las mercancías que entraban en su villa por mar o por tierra, tanto a los vecinos como a los forasteros; que ese año se habían concretado en ciertas tasas fijas para cada bien, caso de 24 mrs. por esclavo, 12 por cada paño entero, 6 por medio, 1 por vara o 6 por cada fustán. Tampoco podía exigir el 2,5\% de lo exportado aunque por los artículos antedichos se tributaba lo mismo que por su importación. A demás, suspendió el cobro de otros derechos nuevamente impuestos relativos a ganados, feria, tiendas, pesos... así como el aumento en las tarifas del portazgo tradicional mente percibido en la localidad o el portazgo recientemente implantado en la torre de Navamulera, en término de dicha población. L uego, en 1502, fue redactado un nuevo arancel de portazgo por los monarcas, que era el único por el que se podía regir su exigencia. Final mente, fue sostenido un pleito entre el procurador fiscal y el citado señor por el almojarifazgo de Gibraleón y sus puertos de Sanlúcar de Guadiana y EI Estanca, sitos en su alfoz, fallado en 1503 en favor del primero en términos iguales a lo visto para los otros surgideros de señorío; para el que también se emitió una sobrecarta en 1516, que contenía la sentencia ejecutoria22.

\subsection{L os comienzos del siglo XV I}

Como se puede apreciar por lo antedicho, la situación sobre la titularidad de los derechos del cargo y descargo en las costas atlánticas andaluzas estaba lejos de haberse resuel to del todo a comienzos del reinado de J uana I. En una carta sin fechar, la soberana encomendaba al corregidor o juez de residencia gaditano que entendiese en una denuncia presentada por J uan de Villa, en nombre del arrendatario del almojarifazgo, Pedro de Santa Cruz, que actuó

\footnotetext{
${ }^{21}$ A HN, SN, Osuna, caja 380, doc. 22.

${ }^{22} \mathrm{AHN}$, SN, O suna, caja 380, docs. 41-43; caja 381, doc. 1. A GS, PR, leg. 36, 21; LC, 3, ff. 12-27, 72-79; LC, 17, ff. 111-113. Ladero 1998, pp. 139, 152-153.
} 
entre 1512-1515. En ella se indica que se le debían grandes cantidades de dinero por parte de distintas autoridades: se cita a los duques de M edina Sidonia, M edinaceli, B éjar y A rcos, y a los condes de Ayamonte y de Niebla; así como por los vecinos y comerciantes de Jerez de la Frontera, Gibraltar, Puerto de Santa M aría, M edina Sidonia, Sanlúcar de Barrameda, Niebla, Huelva, Vejer de la Frontera, Chiclana, Conil, Puerto Real, M oguer, Palos, Gibral eón, Cartaya, San M iguel de A rca de Buey, Sanlúcar de Guadiana, Lepe, Ayamonte, $L$ a R edondela y otros lugares y puertos. El motivo era que se resistían a satisfacer los derechos de la renta, a que sus agentes y guardas residiesen en tales lugares y a que la recaudasen; incluso se temía que fuesen atacados y heridos. De ahí la emisión en 1516 de las sobrecartas más arriba vistas con las sentencias ejecutorias ${ }^{23}$.

De este modo, las haciendas señorial es contaban todavía a principios del siglo XVI con numerosos ingresos provenientes de arbitrios aduaneros 0 portuarios, muy similares o iguales al almojarifazgo real. Parte de ellos provenían de la exportación de vino, uno de los productos más importantes de la zona. Caso de la tabla 0 aduana de $L$ epe y $L$ a Redondela, dedicadas sobre todo a los caldos y frutos, que entre 1490-1497 rentaron unos 600.000-400.000 mrs. y 99.000-77.000, respectivamente; mientras que la tabla y cargazón de Gibraleón sumó 329.110, junto a algunas otras rentas, en 1499; el almojarifazgo y la renta de los paños de Palos de la Frontera, 44.000, en 1503; la calzada de S. Juan del Puerto, 70.000 , en 1509; la calzada y aduana de Huelva, 392.000 y 154.000, también respectivamente, en 1510; la cargazón de los (vinos) bastardos de Trigueros, de 1513, 106.000, y su mesón de la aduana, 130.000; en Cartaya, entre 1518-1523 la renta del muelle (puerto) rondó los 15.000 mrs., mientras que la tabla y cargazón se situó entre los casi 186.000 y los casi 120.000; en S. Miguel de A rca de Buey, por esas fechas, junto con el vino, osciló entre los más de 40.000 y los algo menos de 8.000. Entre 1509-1511, el almojarifazgo de Sanlúcar de Barrameda ascendió a 1,6-1,8 millones de maravedís anuales; en tanto que los de Vejer y M ediana Sidonia rondaban los 200.000, Chiclana, los 100.000, Torre de Guzmán, los 35.000, Conil, Ios 30.000 y Villarrasa, los 10.000. N iebla contaba con un portazgo y una aduana, mientras que su renta de la puerta de la villa, que era una especie de almojarifazgo local con un arancel del $2,5 \%$ de salida, varió entre los 21.500 mrs. y los 38.000, entre 1509 y 1517.

En muchas de estas localidades del al mojarifazgo aduanero se había desagregado una tasa sobre el tráfico mercantil específica para los textiles, que se cobraba aparte o bien, a veces, junto al tributo general, como hemos visto

${ }^{23}$ A GS, CC, Diversos, 3, 57. 
más arriba que ocurrió en Palos. En Niebla había una renta de los paños y ferias, que entre 1509-1511 ascendió a unos 45.000 mrs.; en la vecina Trigueros había otra renta de los paños, durante dichos años de en torno a los 9.000; mientras que en Huelva estaba la renta de los paños de feria, que sumó unos 30.000 mrs., así como la de los sayales, $8.500^{24}$.

Otro ámbito muy importante para la fiscalidad señorial que estuvo relacionado con el mar fue la pesca. Las almadrabas del atún y la actividad económica que sobre ellas orbitaba fueron en gran medida las responsables de que los almojarifazgos de los duques de M edina Sidonia, cobrados en la propia M edina Sidonia, Vejer, Chiclana y Conil, oscilasen entre los 0,5 y 0,6 millones de maravedís hacia 1509-1511. En Palos, sus vecinos habían de descargar sus capturas en la lonja o al ota local, donde había una calzada o desembarcadero. Allí abonaban el 5\% de su precio de venta; al sacarlo del término por mar pagaban el 2,5 y un tanto por carga, si lo hacían por tierra; mientras que el pescado de bajura costero estaba gravado con el 10\%. En 1503 la renta del pescado supuso $46.000 \mathrm{mrs}$. y la de la playa, también sobre las capturas, llegó a los 18.000. La renta del pescado de Huelva fue la mayor, pues este puerto acabó por desbancar al anterior, pasando de los $400.000 \mathrm{mrs}$. en 1493 a los más de 618.000 de 1504; entre 1509-1511 se situó de nuevo en torno a los 400.000 y se completó con otras como la del lavar de la sardina (15.000), el millar de la sardina (18.000) y la sardina ahumada (20.000). Por su parte, en Sanlúcar de B arrameda la renta del pescado osciló en torno a los 130.000 mrs. anuales, hacia 1509-1511; años en los que en San J uan del Puerto llegó hasta los 70.000, y en Trigueros a los 60.000. Sin embargo, en A Imonte, B eas, Rociana y Niebla no superó los 13.000; en G ibral eón apenas al canzó los 29.000, en 1499; y, todavía menor fue en Cartaya y S. M iguel de A rca de Buey, entre $1518-1526^{25}$.

\section{Prestigio político}

L a titularidad o control sobre ciertos impuestos real es no solo interesó a los aristócratas para nutrir sus haciendas, sino que éstos fueron también fuente de otras ventajas inmateriales e intangibles, que se podían traducir en una más elevada posición social y reportar por ello nuevos bienes materiales. Se trató, sobre todo, del prestigio y poder político que otorgaban ingresos que como el almojarifazgo gravaban el comercio exterior. A sí, como hemos podi-

\footnotetext{
${ }^{24}$ Ladero 1998, pp. 225-227; Solano 1972, pp. 103, 115-127; N avarro 1988, pp. 341-342.

25 Solano 1972, pp. 103-104, 115-127; Ladero 1992, pp. 109-110, 113-114, 116; Ladero 1998, pp. 153-155, 186-187; N avarro 1988, pp. 326, 331-332, 341.
} 
do comprobar, la carga ideológica que conllevaba la posesión de esta exacción hizo que al gunos de los más al curniados personajes, cuando no pudieron mantener la gestión directa de su recaudación, procuraron continuar vinculados a él mediante la participación en su arrendamiento 0, cuando menos, intentaron seguir beneficiándose de su rendimiento a través de juros.

Como es sabido, la práctica totalidad de la nobleza castellana, así como buena parte del clero y algunos miembros de la oligarquía urbana, fueron beneficiarios de juros con los que los reyes premiaron sus servicios, situados sobre los principales impuestos de la Corona. En ocasiones, muchos de ellos fueron designados, además, como funcionarios o continos reales, u obtuvieron algún cargo remunerado en la corte 0 en los concejos de las principales ciudades, a propuesta de los monarcas. Este fue el caso, entre otros, de los Ponce de León que, por ejemplo, recibieron juros en los almojarifazgos de Sevilla y Jerez de la Frontera, o fueron alcaldes mayores de la primera y al guaciles mayores de la segunda ${ }^{26}$.

Esto no obstó para que al gunos poderosos personajes se comportasen a su vez como gobernantes dadores de gracias y mercedes con sus propios deudos y vasallos, similares a las por ellos recibidas de las manos reales, a las que imitaron, por tanto. Durante la guerra civil que enfrentó a Enrique IV con su hermanastro A Ifonso, proclamado rey en Guisando, J erez y Sevilla tomaron partido por este último, de manera que en 1466 los alcaldes mayores de la segunda, Enrique de Guzmán, duque de M edina Sidonia, y Rodrigo Ponce de León, conde de A rcos, comunicaron al concejo de la primera que el príncipe había concedido a algunos de sus paniaguados (J uan de Pineda, escribano mayor del concejo, y Pedro Gallegos, veinticuatro y teniente de alcalde mayor, por el bando del conde; y por el otro bando, al secretario del duque y a su médico, Juan Rodríguez) ciertas sumas del almojarifazgo sevillano. Como parte de ellas pertenecían a lo recaudado en J erez, ordenaron a su consistorio que no se opusiese a su entrega ${ }^{27}$.

En la ciudad de A rcos de la Frontera, sede central de la casa de los Ponce de L eón, sus señores actuaron con su al mojarifazgo y otras rentas como los reyes con el de Sevilla y otros, pues otorgaron juros sobre ellas a sus subordinados. En concreto, el III conde de A rcos y I marqués de Cádiz (luego

${ }^{26}$ En 1468 el duque de M edina Sidonia protestó ante el concejo de Jerez porque éste había embargado ciertos derechos del almojarifazgo local que afectaban a los juros de los que él se beneficiaba, que le habían sido concedidos en el almojarifazgo mayor de Sevilla, en el que se incluía una parte del jerezano, así como sobre las rentas menudas de dicho almojarifazgo mayor, para sostener la ciudad de Gibraltar recientemente conquistada al Islam y dada al citado duque; A M J F, A C , 1468, ff. 142v-143r. M ientras, el duque de Béjar tenía juros en el almojarifazgo del pescado salado de Sevilla; AHN, SN, O suna, carpeta 86, doc. 8.

${ }^{27}$ A M JF, A C 1468, f. 54r-v. 
I duque), Rodrigo Ponce de León, obsequió en 1472 a Pedro de Vera, al caide de A rcos, en agradecimiento por la toma para el marqués de la villa de Cardela, donde fue herido, con 10.000 mrs. de juro de heredad situado en su almojarifazgo arcense. Dicho juro fue traspasado por su beneficiario al monasterio de Santo Domingo de J erez, según confirmación de 1512 del nieto del I duque de Cádiz, el I duque de A rcos. J uan deAyllón, que también participó en la toma de Cardela, consiguió por juro de 3.000 mrs. Posteriormente, en 1483, el III conde concedió otros situados igualmente sobre el almojarifazgo arcobricense a varios personajes, en agradecimiento por su ayuda en la conquista de Zahara a los granadinos. A sí, Fernando de Padilla, alcaide y alcalde mayor de Arcos, obtuvo un juro de heredad de 10.000 mrs., que cobraría por cuatrimestres con solo mostrar la copia del privilegio dado por el marqués y tras firmar a los arrendatarios la correspondiente carta de pago; los cuales serían tenidos en cuenta a los anteriores por el contador del señor. En iguales términos recibieron juros A ntón M artín de Espinosa (3.000 mrs.), J uan de A Imario (2.000), García Tardío (2.000), Fernando Tardío (2.000) y M artín de M orón (3.000), por haber subido por la escala con la que se tomó la plaza. A demás, para mayor similitud con las mercedes reales, los sucesores del conde R odrigo confirmaron estos privilegios, caso de su mujer, Beatriz Pacheco, la duquesa viuda, en 1492, y de su nieto Rodrigo, el I duque de Arcos, en 1511 y 1516. Fueron unas concesiones realizadas en términos parecidos al juro obtenido por el propio III conde, en 1469, cuando Enrique IV le dio 100.000 mrs., primero sobre las alcabalas sevillanas, luego sobre el al mojarifazgo mayor, privilegio confirmado por los R eyes Católicos en 1476.

Como acabamos de ver más arriba, estos juros podían ser traspasados, donados o vendidos, total o parcialmente, de forma que no siempre permanecieron en manos de los beneficiarios originales o sus herederos. A demás, a veces se podían desatar pleitos por el cambio de titularidad de las localidades y rentas sobre las que estaban asentadas dichas mercedes, que en ocasiones no eran reconocidas por los nuevos señores. A sí ocurrió en 1513, cuando se hizo un traspaso de un juro de 3.000 mrs., también situados sobre el almojarifazgo arcobricense, que poseía un vecino de M orón, en favor de un recaudador del aristócrata de su ciudad ducal, a cambio de una casa propiedad del mismo. En otras ocasiones, los juros eran amortizados y retornaban a los señores. A sí pasó en 1522, cuando un vecino de A rcos vendió al I duque uno de 2.000 mrs. anuales, sitos sobre el almojarifazgo local, a cambio de 18.000. M ás adelante, entre 1528-1535, los señores de A rcos compraron los juros dados por el III conde con motivo de la toma de Zahara, arriba vistos, por los que pagaron a los familiares de los perceptores iniciales 15.000 mrs. por uno de los juros que rentaba 2.000 anuales, y 24.000 por otro de la misma cuantía; otro de ellos estaba dividido entre dos beneficiarios, de modo que por 1.000 mrs. entregaron 
13.000; mientras que el juro de 10.000 mrs. se hallaba repartido también entre varios herederos, uno que tenía 5.000 obtuvo 40.000 , y otros dos que gozaban cada uno de 2.500, 25.000 por cabeza ${ }^{28}$.

A demás de actuar como soberanos dadores de gracias a sus favoritos y vasall os a partir de sus rentas, los señores de A rcos imitaron a los reyes castellanos en la forma de arrendar las exacciones que componían su patrimonio, de manera que los derechos señorial es fueron gestionados de manera similar a los impuestos reales. En 1409 el titular de la villa de A rcos de la Frontera era el condestable de Castilla, Ruy López Dávalos, quien ordenó el arrendamiento del almojarifazgo de la localidad según las condiciones en que se había hecho en los años precedentes. Esto es, el adjudicatario debía dar fiadores cuantiosos y abonados en el plazo de tres días tras ser rematado a contentamiento de su hacedor, que debía ser el contador del señor o su mayordomo; de lo contrarío, el arbitrio sería de nuevo subastado. El recaudador tenía que entregar lo comprometido en el arrendamiento tres veces al año, cada cuatrimestre, así como satisfacer sus derechos al escribano. O tras tasas de cancillería que había de abonar eran el $1 \%$ del arrendamiento al hacedor señorial y al escribano del concejo local, así como 40 mrs. por la carta de recudimiento y otros 20 para pagar al pregonero. Tras ser rematada la renta, quedaba abierta a sobrepujas durante 4 meses, para que si alguien ofrecía más que el último postor se la pudiese adjudicar. Dichos oferentes serían premiados con el sesmo, o 1/6 de lo sobrepujado en caso de que finalmente no resultasen adjudicatarios, para estimular la presentación de ofertas en las subastas. A parece tachado que quienes ofertasen más de 20.000 mrs. serían bonificados con el $10 \%$ de lo pujado. El arrendatario debía correr con los riesgos de la recaudación, por lo que no sería indemnizado o perdonado en caso de no al canzar los objetivos previstos, salvo si el condestable mandaba embargar la renta, en cuyo caso entregaría solamente la parte proporcional del período en el que se mantuvo vigente el arrendamiento. En el de 1421, que abarcó 18 meses, ya consta quien era el factor del condestable encargado de llevarlo a efecto: se trató de Ferrand $M$ árquez, su escribano y mayordomo. $L$ as condiciones fueron las antedichas, si bien variaron en otro arrendamiento del que desconocemos la fecha, que se hizo por cuatro años. En el primero no se podía pujar la renta para arrebatársela al adjudicatario, pero sí durante los tres siguientes. Las únicas ofertas admisibles serían las pujas de diezmo, medio diezmo, tercio o de cuarto, esto es, solamente se podía sobrepujar el 10, 5, 33 o el 25 por ciento del precio por el que estaba rematada. Los arrendatarios del primer año fueron Diego García,

${ }^{28}$ A HN , SN, Osuna, caja 118, docs. 57-59, 149-154; caja 120, docs. 23-27; caja 121, docs. 2, 24-34; caja 143, doc. 9; caja 1.551, docs. 1-7; carpeta 66, doc. 2; carpeta 24, doc. 1; carpeta 38 , doc. 15. 
Diego M artínez y Juan González, y se estableció que si a partir del segundo les era arrebatado el arrendamiento, percibirían 1/4 de la primera puja que sobre el mismo se realizase, a pagar por el nuevo adjudicatario, con lo recaudado en el primer tercio del año, mientras que los ofertantes se quedarían con el sesmo. La fianza a aportar por los arrendatarios era de la mitad de lo comprometido y de cada anual idad debería darse cuenta por separado, mientras que lo recaudado se abonaría cada año en un primer plazo a los cinco meses, en otro segundo, cuatro meses después, y el último, a los tres meses ${ }^{29}$.

En 1497 la duquesa viuda, Beatriz Pacheco, realizó una serie de reformas de los cuadernos de arrendamiento de la renta. Entre ellas, dispuso que los pleitos y desavenencias desatados entre los arrendatarios y cualesquier otras personas serían atendidos por los al caldes arcenses, sumariamente, de manera que el demandado solo dispondría de tres días para responder a la querella y no se podrían emplear abogados, salvo si los quisiesen los almojarifes. Se mantenía la cláusula de los fiadores por la mitad del valor de lo arrendado, en el plazo de los dichos tres días, pero en este caso a contentamiento de los alcaldes urbanos, como ocurría en J erez con el almojarifazgo real. L as pagas debían hacerse por tercios anuales, como anteriormente, pero ahora podían ser embargados los posteriores si no satisfacía una de ellas. Además, las nuevas tasas de cancillería serían del $0,1 \%$ para el contador ducal por la carta de recudimiento, del $1 \%$ al susodicho y al escribano por su trabajo, y 20 mrs. para el pregonero. El primer día del año los alcaldes debían nombrar fieles juramentados para recaudar la renta hasta que ésta fuese rematada, quienes debían ser acaudal ados y cuantiosos para que pudiesen responder de su gestión y tenían que dar cuenta de ésta a los adjudicatarios del arrendamiento, en el plazo de tres días desde que se hiciesen cargo del mismo. En 1498 la aristócrata prohibió hacer ligas o impedimentos en el arrendamiento para bajar su precio, y estableció que las pujas tras el remate solamente podían ser de cuarto, sin prometido alguno y en un plazo máximo de dos meses ${ }^{30}$.

U na última forma de emulación nobiliaria del poder regio en materia fiscal consistió en la fundación de nuevas localidades, a cuyos pobladores se atrajo mediante la exención o rebaja de exacciones, el almojarifazgo entre ellas; tal como hicieron los monarcas en estas tierras de la baja A ndalucía, tras

${ }^{29}$ A H N , SN , Osuna, caja 116, docs. 36-42; L adero 1998, p. 82; Carriazo 2014; Solano 1972, p. 86 . En 1451 el almojarifazgo arcense fue arrendado por Pedro A rias, vecino de la villa, por $34.000 \mathrm{mrs}$. A parte, resultaron arrendadas la renta del cornado de la carne, la del tablero de los dados, la de las varas de los paños y la del diezmo y medio diezmo de lo morisco; A HN, SN, Osuna, caja 117, doc. 5.

${ }^{30}$ A HN , SN , O suna, caja 120, docs. 2-3; Solano 1972, pp. 91-92, 156-168. 
la conquista del siglo X III. A sí, en 1477, el I marqués de Cádiz y III conde de Arcos, Juan Ponce de L eón, fundó el lugar de Chipiona, donde con probabilidad existía previamente una aldea perteneciente al término de Rota. Con el fin de atraer a nuevos habitantes, el señor concedió una carta puebla. En ella se les eximía durante los primeros quince años de todo tipo de tributos (pedidos, monedas, servicios... reales y concejiles), e incluso los liberó del pago de almojarifazgo y alcabalas, tanto en la propia Chipiona como en Rota; si bien debían comunicar sus tratos con forasteros al recaudador/arrendatario señorial de estos derechos. Tales forasteros sí correrían con estas tributaciones, aunque obtuvieron sustanciales rebajas en comparación a lo que se demandaba en Sevilla. Durante los cinco años iniciales de la fundación solo satisfarían de almojarifazgo el $2,5 \%$ y el 5 en concepto de alcabala, mientras que en adelante ambos quedaron en el 5-10\%, respectivamente. Trascurridos los quince años de gracia, los nuevos pobladores pagarían los mismos derechos que los roteños, incluidos almojarifazgo y alcabala. De ello se podría deducir que los repobladores iniciales quedaron exentos de por vida, pues las punciones fiscales solo afectarían a los nuevamente avecindados; al go que no es posible asegurar con rotundidad debido a las lagunas de la copia de la carta puebla que nos ha llegado. A sí parece, sin embargo, que lo interpretó el concejo local, que entendía que cual quiera que allí fuese a vivir estaría exonerado durante el citado plazo y, por ello, en 1491-1492, se quejó ante el ahora I duque de Cádiz (antes I marqués) de que los arrendatarios, pasado ya el intervalo, reclamasen tasas a los lugareños por sus ventas. A lo que R odrigo Ponce respondió que éstas fuesen cargadas sobre los forasteros cuando adquiriesen artículos de los vecinos. Posteriormente, para evitar que dejasen de afluir moradores, el consistorio reclamó al año siguiente de la duquesa viuda, la antedicha Beatriz Pacheco, que se aclarasen las franquezas contenidas en la carta puebla.

He aquí uno de esos puertos que los R eyes Católicos denunciaron que habían sido abiertos sin su licencia, como vimos más arriba, en el que el aristócrata se permitió suprimir temporalmente la exigencia de dos impuestos reales de la mayor relevancia económica e ideológica, como eran el almojarifazgo y la alcabala, sobre los que pretendía tener jurisdicción en sus tierras patrimoniales. En tiempos de la viuda, hacia 1493 se habría comenzado la construcción de un muelle para mejor acoger el creciente tráfico naval y comercial a que dieron ocasión las franquezas antedichas. Con él, los titulares del señorío pretendían asentar en el lugar una flota mercante, además de servir de refugio a los barcos foráneos. Para mayor potenciación de este naciente enclave portuario, el concejo solicitó de B eatriz Pacheco que exonerase de por vida a los hombres de mar, como ocurría en otros surgideros de la comarca; puede que se refirieran a la exención de pechos señoriales o del propio almojarifazgo, caso este último que nos recuerda al de los bretones de Sanlúcar de 
B arrameda, anteriormente mencionado. No obstante, entre las rentas percibidas por la casa de A rcos de comienzos del siglo X VI no aparece nada relativo al almojarifazgo ni a las alcabalas chipioneros, así como tampoco a los derechos sobre el pescado, Io que para Franco Silva resulta sorprendente; si bien quedaría perfectamente explicado tras los litigios arriba vistos, gracias a los cuales fueron restituidos estos arbitrios, al menos el primero temporalmente, a la Hacienda regia ${ }^{31}$.

En 1494, la casa rival de los Ponce de León, la de Medina Sidonia, se inspiró en la carta puebla de fundación dada por los primeros a Chipiona, para conceder otra similar a Trebujena, con la que segregarla de Sanlúcar de Barrameda. Sin embargo, fueron más restrictivos. La franqueza inicial se redujo a solo diez años. Eso sí, serían los primeros que pasase en la localidad cada nuevo habitante; si bien más adelante en una adición fueron ampliados a quince, como en Chipiona. A demás, la exención solo incluía al cabala, para los productos locales, a pesar de que la nueva puebla contaba con un puerto propio, en el Guadalquivir, en el donadío de A Iventos, en el que se podía haber dejado de demandar, o al menos rebajado, el al mojarifazgo del que con pleno derecho sí gozaban los Pérez de G uzmán. A ntes bien al contrario, en 1496 el concejo de Jerez de la Frontera protestó ante el duque porque allí se exigían nuevos derechos nunca cobrados sobre las mercancías que por él entraban o salían, hacia o desde, dicha ciudad. No obstante, no hemos de olvidar que las citadas alcabalas puede que fuesen las al cabalas viejas que se comprenderían en el almojarifazgo local ${ }^{32}$.

Pero, tal vez, la mayor emulación de los duques de M edina Sidonia Ilevada a cabo en Sanlúcar con respecto a la actuación de los monarcas castellanos en materia comercial y fiscal fue crear una casa de contratación, que ya existía en 1507, similar a la fundada por los Reyes Católicos en la cercana Sevilla33.

\section{CONCLUSIÓN}

El fortalecimiento de la aristocracia andaluza estuvo sustentado económicamente en la captación de nuevas fuentes de ingreso, generalmente procedentes de exacciones y derechos obtenidos del erario real, que cobraban en su favor, pero también de los nuevos territorios bajo su jurisdicción que ganaron gracias a su posición cercana a los reyes. $L$ a voracidad de los grandes

${ }^{31}$ Franco 1998, pp. 247-287.

32 González 1984, pp. 381-382. A M J F, A C 1496, ff. 227v-228r.

${ }^{33}$ Galán 1990, p. 74. 
nobles no conoció en materia fiscal casi ningún límite. Cuando los monarcas no les cedieron la práctica totalidad de los impuestos exigidos en sus dominios territoriales, se limitaron a expoliarlos o a cobrarlos en su nombre total o parcialmente. Incluso expropiaron rentas en teoría pertenecientes a los bienes de propios de los concejos bajo su jurisdicción. En general, ésta fue una realidad bastante extendida en toda la Corona, pero que en las costas y fronteras del reino alcanzó sus consecuencias más graves, pues uno de los principales arbitrios de los que se nutría la monarquía eran las aduanas exteriores, que los grandes señores también quisieron para sí. El caso más extremo fue la cesión a la familia de los Condestables de Castilla, hasta bien entrado el siglo $\mathrm{XVI}$, del diezmo de la mar de los puertos del norte peninsular. Frente a esta donación de derecho, los marqueses de Villena pretendieron algo parecido y durante el reinado de Enrique IV se hicieron de hecho con el cobro del diezmo aduanero con el reino de Valencia, exigido en sus dominios ${ }^{34}$.

Desde comienzos del siglo XIV, y gracias a su importancia en la zona, debido al permanente estado de guerra que se vivía, primero por la amenaza de los benimerines y luego de los granadinos, las grandes casas nobiliarias intentaron conseguir los impuestos aduaneros costeros de sus respectivos señoríos, conocidos como almojarifazgo o derechos del cargo y descargo de la mar. A Igunas veces lo lograron más o menos legalmente, al estilo de los condestables, caso de los señores de M edina Sidonia y su almojarifazgo de Sanlúcar de B arrameda, o de los de A rcos, y el suyo de Cádiz. O tras, hubieron de recurrir a la vía de los hechos consumados, como ocurrió en el marquesado de Villena y en el resto de la costa atlántica andaluza. En el primer caso fueron las necesidades bélicas las que llevaron a los soberanos a realizar estas excepcionales cesiones en favor de los dos mayores linajes de la región, mientras que en el segundo los sucesivos titulares de los estados señoriales aprovecharon las coyunturas de debilidad monárquica para incluir entre sus rentas tal es gravámenes.

Una vez revertidas ambas situaciones, la inseguridad fronteriza tras el fin de la guerra contra Granada y la precariedad del poder real con el afianzamiento de una monarquía nacional, los Reyes Católicos comenzaron a finales de la década de 1480 una política que consistió tanto en la reforma de la Hacienda real y en la reducción de algunas cargas existentes sobre ella, tales como los juros, como en la creación de nuevas fuentes de ingreso y en la recuperación e incremento de las tradicionales, tras rescatarlas de instancias señoriales. La estrella de dicho rescate fue, sin duda, el almojarifazgo, uno de los impuestos más relevantes por el volumen de recaudación. En especial

${ }^{34}$ González 2014. 
el de Sevilla, ciudad que por entonces era una de las de mayor importancia económica de la Corona. En este régimen de tesorería se incluyeron, entre otros tributos también rehabilitados, como el diezmo del aceite del A ljarafe, los aduaneros de la costa atlántica andaluza; de los que los monarcas tuvieron que desposeer a sus usurpadores a través de una serie de pleitos, que no culminaron hasta bien entrado el siglo XVI, pero que sentaron precedentes para recuperar el dominio fiscal del poder central frente a los señores territoriales, base de la propia monarquía autoritaria que se inició en este reinado.

Por todo ello, este trabajo puede servir de ejemplo sobre cómo fue iniciada la construcción del Estado moderno por parte de los Reyes Católicos. En este caso a través de la casi total recuperación para el erario regio de uno de los impuestos de mayor trascendencia, por su volumen de ingresos y por servir de regulador sobre el comercio exterior del sur peninsular. Se trató de un episodio más en la lucha entre la monarquía y la aristocracia castellanas por el control del poder que se iniciara para al gunos con A Ifonso XI, mientras que para otros lo hizo con A Ifonso $X$, y que tuvo en este campo de batalla de la fiscalidad uno de sus escenarios principales, por haberse convertido en una de las fuentes de financiación fundamentales para ambas partes. Si bien a lo largo de toda la baja Edad M edia los avances centralizadores fueron seguidos de importantes retrocesos, la novedad que supuso este reinado fue que las reformas en él introducidas, como ésta aquí estudiada del dominio aduanero de la costa atlántica andaluza, ya no tendrían marcha atrás.

\section{BIBLIOGRAFÍA CITADA}

Aznar Vallejo, Eduardo; Palenzuela D omínguez, Natalia (2009), El comercio andaluz en 1502. Las fuentes fiscales, en Val Vadivieso, M aría Isabel del; M artínez Sopena, Pablo (dirs.), Castilla y el mundo feudal. H omenaje al profesor J ulio Valdeón, Valladolid, Universidad de Valladolid, vol. I, pp. 673-689.

Carande, Ramón; Carriazo A rroquia, Juan de M ata (1968), El Tumbo de los Reyes Católicos del concejo de Sevilla, Sevilla, Editorial Católica Española.

Carriazo Rubio, Juan Luis (2014), Notas sobre fiscalidad señorial: el almojarifazgo de Arcos de la Frontera a comienzos del siglo XV, en B orrero, M ercedes; Carrasco, Juan; Peinado, Rafael G. (eds.), Agentes de los sistemas fiscales en Andalucía y los reinos hispánicos (siglos XIII-XVII): un modelo comparativo, Madrid, Instituto de Estudios Fiscales, pp. 193-210. 
Fernández Gómez, M arcos; Ostos Salcedo, Pilar; Pardo Rodríguez, M aría L uisa (1997), El tumbo de los Reyes Católicos del concejo de Sevilla, $M$ adrid, Fundación Ramón A reces.

Franco Silva, A Ifonso (1998), La organización municipal de Chipiona a través de sus ordenanzas, en Franco Silva, A Ifonso (ed.), Estudios sobre ordenanzas municipales (siglos XIV-XVI), Cádiz, U niversidad de Cádiz.

Galán Parra, I sabel (1990), Las ordenanzas de 1504 para Huelva y el Condado de Niebla, "Huelva en su Historia" 3, pp. 107-174.

Gonzál ez A rce, J osé D amián (2012), Los beneficiarios de la fiscalidad medieval. El caso del diezmo del aceite del almojarifazgo de Sevilla en el siglo XV, "M edievalismo" 22, pp. 99-137.

González Arce, José Damián (2014), Actividad económica y exacciones fiscales. EI almojarifazgo de J erez en los siglos XIII-XV, en Sánchez Herrero, J osé; González J iménez, M anuel; B area R odríguez, M anuel A ntonio (dirs.), 750 aniversario de la incorporación de J erez a la Corona de Castilla: 1264-2014, Jerez de la Frontera, Ayuntamiento de Jerez, pp. 221-247.

González Jiménez, M anuel (1984), La Carta-Puebla de Trebujena (1494), "Historia. Instituciones. Documentos" 11, pp. 375-385.

Ladero Quesada, M iguel Ángel (1969), Almojarifazgo sevillano y comercio exterior de Andalucía en el siglo XV, "A nuario de Historia Económica y Social" 2, pp. 70-115.

Ladero Quesada, M iguel Á ngel (1974), U nas cuentas en Cádiz (1485-1486), "Cuadernos de Estudios M edievales" 2-3, pp. 85-120.

Ladero Quesada, M iguel Ángel (1982a), Fiscalidad regia y sector terciario en la Andalucía bajomedieval, en Hacienda y comercio: actas del II coloquio de Historia Medieval Andaluza, Sevilla, 8-10 de Abril, 1981, Sevilla, Diputación de Sevilla, pp. 7-38.

Ladero Quesada, M iguel Ángel (1982b), Los señoríos medievales en el ámbito de Cádiz y Jerez de la Frontera, "En la España medieval" 2, pp. 543-572.

Ladero Quesada, M iguel Á ngel (1992), Niebla, de reino a condado. Noticias sobre el Algarbe andaluz en la baja E dad M edia, M adrid, Real A cademia de la Historia.

Ladero Quesada, M iguel Ángel (1998), Los señores de Andalucía. Investigaciones sobre nobles y señoríos en los siglos XIII a XV, Cádiz, Universidad de Cádiz.

Ladero Quesada, M iguel Ángel (2009), La Hacienda Real de Castilla, 13691504, M adrid, Real A cademia de la H istoria.

Ladero Quesada, M iguel Á ngel (2012), Sanlúcar de Barrameda, antepuerto de Sevilla, a finales del siglo XV, en M undos medievales: espacios, 
sociedades y poder: homenaje al profesor J osé Ángel García de Cortázar y Ruiz de Aguirre, Santander, U niversidad de Santander, vol. II, pp. 1491-1508.

M oreno Ollero, A ntonio (1983), Sanlúcar de Barrameda a fines de la Edad Media, Cádiz, Diputación de Cádiz.

Navarro Sáinz, José M aría (1988), Aspectos económicos de los señoríos de los duques de Medina Sidonia a principios del siglo XVI, "Huelva en su Historia" 2, pp. 319-345.

Nieto Soria, J osé M anuel (2007), Castilla y la europeidad política en tiempos de Isabel I, en Casado A Ionso, Hilario; García-B aquero, A ntonio (eds.), Comercio y hombres de negocios en Castilla y Europa en tiempos de Isabel la Católica, Madrid, M inisterio de Cultura, pp. 25-43.

Palenzuela D omínguez, Natalia; A znar Vallejo, Eduardo (2010), El comercio de los puertos del Condado en 1502. El testimonio del almojarifazgo, "Huelva en su Historia" 13, pp. 63-133.

Quintanilla Raso, M aría Concepción (1982a), Haciendas señoriales andaluzas a fines de la Edad Media, en Hacienda y comercio: actas del II coloquio de Historia Medieval Andaluza, Sevilla, 8-10 de Abril, 1981, Sevilla, Diputación de Sevilla, pp. 53-65.

Quintanilla Raso, M aría Concepción (1982b), H aciendas señoriales nobiliarias en el reino de Castilla a fines de la Edad Media, en Historia de la Hacienda Española (Épocas Antigua y Medieval). Homenaje al profesor García Valdeavellano, M adrid, M inisterio de Hacienda Instituto de Estudios Fiscales, pp. 767-798.

Romero M edina, Raúl (2009), Almojarifazgo portuense o los derechos de carga y descarga: el cobro de los situados aduaneros del comercio marítimo (1489-1541), "Revista de Historia de El Puerto" 42, pp. 35-62.

Salas A Imela, Luis (2014), EI Puerto de Santa María en la primera mitad del siglo XVI: un conflicto antiseñorial en clave Atlántica, en Borrero Fernández, M ercedes; Carrasco Pérez, J uan; Peinado Santaella, Rafael G. (eds.), Agentes de los sistemas fiscales en Andalucía y los reinos hispánicos (siglos XIII-XVII): un modelo comparativo, Madrid, Instituto de Estudios Fiscales, pp. 291-316.

Solano Ruiz, Emma (1972), La hacienda de las casas de Medina Sidonia y Arcos en la Andalucía del siglo XV, "A rchivo Hispalense" 55/168, pp. 85-176.

Fecha de recepción del artículo: febrero 2014

Fecha de aceptación y versión final: marzo 2015 